\title{
Attitudes of final-year dental students to bleaching of vital and non-vital teeth in Cardiff, Cork, and Malmö
}

\author{
S. HATHERELL*, C. D. LYNCH ${ }^{\dagger}$, F. M. BURKE ${ }^{\ddagger}$, D. ERICSON ${ }^{\S} \&$ A. S. M. GILMOUR ${ }^{\mathbb{I l}}$ \\ "School of Dentistry, Cardiff University, ${ }^{\dagger}$ Tissue Engineering $\theta$ Reparative Dentistry, School of Dentistry, Cardiff University, Cardiff, UK, \\ ${ }^{\ddagger}$ Restorative Dentistry, Dental School, University College Cork, Ireland, ${ }^{\S}$ Faculty of Odontology, Malmö University, Malmö, Sweden and \\ "Learning ef Scholarship, School of Dentistry, Cardiff University, Cardiff, UK
}

SUMMARY The aim of this study was to determine attitudes of final-year dental students in Cardiff, Cork and Malmö towards tooth whitening. Following receipt of ethical approval, pre-piloted questionnaires were distributed to final-year dental students in Cork, Cardiff, and Malmö as close as possible to graduation. The questionnaire sought information relating to various opinions and attitudes towards the use of bleaching techniques including safety of bleaching, confidence in the provision of bleaching, recommendations to patients, teaching received, awareness of restrictions on the use of bleaching products and management of simulated clinical scenarios. Eighty three per cent $(n=116)$ of questionnaires were returned. Cork dental students had the most didactic teaching (2- $h$ vital, $1-h$ non-vital bleaching) compared to Cardiff or Malmö students ( $0 \mathrm{~h}$ each). More Cork students regarded bleaching as safe $(76 \%, n=28)$ than Cardiff $(70 \%, n=32)$ or Malmö $(36 \%, n=12)$ students. More than $50 \%$ of Cork students feel they know enough about bleaching to provide it in practice, significantly more than Cardiff $(<25 \%)$ or Malmö $(<25 \%)$ students. The majority of students would provide vital bleaching after qualification ( $100 \%(n=37)$ Cork; $82 \%(n=27)$ Malmö; $76 \%$ $(n=35)$ Cardiff). In simulated clinical scenarios, more Cork students would propose bleaching treatments $(89 \% n=33)$ than Malmö $(64 \% n=21)$ or Cardiff $(48 \%$ $n=22$ ) students. Variations exist in the attitudes and approaches of three European dental schools towards bleaching. Dental students need to be best prepared to meet the needs of their future patients.

KEYWORDS: bleaching, whitening, dental students, education, aesthetics

Accepted for publication 31 July 2010

\section{Introduction}

Over the years, there have been changing shifts in the range of dental procedures carried out in Western society. While there has been a general fall in caries and increased tooth retention, patients are increasingly demanding aesthetic dentistry, as more patients strive for a 'perfect smile' (1-4). With changes in priorities and influences from the media, many people desire faultlessly white teeth; however, some patients present with genuine intrinsic or extrinsic staining. These can be caused by a number of factors, including dietary influences, tobacco, tetracycline and other internal staining such as that caused by the breakdown of blood products after endodontic treatment $(5,6)$.

When teeth are stained or discoloured, several treatment options are currently available. Some, such as crowns and veneers, offer a more destructive approach; for example, a study has found that up to $15.6 \%$ of teeth restored with metal ceramic crowns became non-vital within 10 years following active treatment (7). Lower levels of pulpal damage should be expected for veneers where less tooth tissue is removed and preparations should not invade dentine. Other options available can be seen to preserve tooth tissue, including microabrasion and bleaching (vital and 
non-vital) $(5,8)$. While bleaching techniques offer a non-destructive approach, they are not without disadvantages, with side effects including tooth sensitivity, soft tissue irritation and effects on both dental hard tissues and restorative materials (4). Furthermore, there have also been reports of cervical root resorption following intra-coronal non-vital bleaching $(6,9,10)$.

With potential side effects, concerns have been raised regarding the safety of bleaching teeth with high concentrations of hydrogen peroxide (shown to have greater prevalences of adverse reactions), particularly when used by non-dental professionals such as allegedly occurring in beauty salons amongst others (4). The European Union's (EU) Cosmetics Directive (European Council Directive on Cosmetic Products 76/768/EEC and subsequent amendments) (11) defines a 'cosmetic product' and restricts the level of hydrogen peroxide (or levels produced) in such products to a maximum $0.1 \%$ (12). This has direct effects on dental bleaching techniques and although the techniques of internal and external bleaching are not illegal, the supply of necessary materials is not permitted. However, this situation varies around the EU because of conflicting classifications. The United Kingdom (12) and Ireland (13) classify whitening products as cosmetics, while Spain classifies them as dental devices, and Sweden as medical devices (14). Further to this, the courts in the United Kingdom have clarified the interpretation of domestic legislations where the supply of any cosmetic whitening product containing more than $0.1 \%$ hydrogen peroxide is prohibited (12).

The EU Cosmetics Directive (11) has potential impacts on the teaching in European dental schools, with students having varying amounts of exposure to and teaching of bleaching techniques that are potentially available. This can lead to consequences in general dental practice, as dental students are likely to continue the approaches towards treatment that they learnt at dental school. Furthermore, under current EU freedom of movement legislation, it is possible for dentists trained in EU countries to move within the EU. Final-year dental students are the dentists of the future, and many will be practicing for the next forty years (15). Their current attitudes are important, and this project will aim to discuss their viewpoints towards tooth bleaching. The aim of this project was to examine the attitudes of final-year dental students towards dental bleaching in Cardiff, Cork and Malmö dental schools.

\section{Materials and methods}

Ethical approval was obtained from the Cardiff University Medical and Dental School Research Ethics Committee. Pre-piloted questionnaires were distributed to a small number of teaching staff, following which prepiloting, minor grammatical changes and phraseology amendments were included to make the questions and scenarios more clear. Paper-based questionnaires were then distributed to final-year dental students in Cardiff $(n=57)$, Cork $(n=38)$ and Malmö $(n=45)$. These were distributed half way through the final year, as near as possible to graduation to reflect the opinion the students are likely to have on qualification. Completing the questionnaire was entirely optional and answers anonymous, with information about the study provided to participants.

The questionnaire contained both 'open' and 'closed' questions including the following areas:

1 attitudes to the safety of bleaching;

2 confidence in the provision of bleaching;

3 attitudes to provision of bleaching and recommendations to patients;

4 teaching received in bleaching;

5 awareness of restrictions on the use of bleaching products;

6 management of simulated clinical scenarios.

Data collected from the questionnaires were entered and analysed using SPSS version 16.0.* Descriptive statistics are reported.

\section{Results}

The overall response rate was $83 \%(n=116)$ with $81 \%$ from Cardiff $(n=46), 97 \%$ from Cork $(n=37)$ and $73 \%$ from Malmö $(n=33)$.

\section{Attitudes to the safety of bleaching}

When asked their opinion on the statement 'Vital tooth bleaching is safe', the majority of Cardiff $(70 \%, n=32)$ and Cork $(76 \%, n=28)$ students agreed, although a greater number of Cork students 'strongly agreed'. However, $15 \%(n=5)$ of Malmö disagreed with the statement, and $49 \%(n=16)$ regarded themselves to be 'neutral'. This is illustrated in Fig. 1, where although no students 'strongly disagreed', Malmö students

*SPSS Inc., Chicago, IL, USA. 


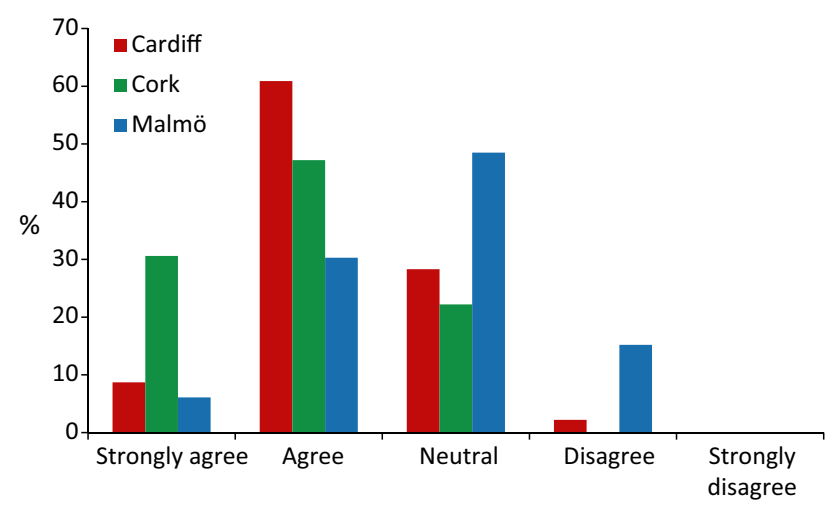

Fig. 1. Agreement with statement 'Vital tooth bleaching is safe'.

were more negative towards the safety of vital tooth bleaching.

\section{Confidence in the provision of bleaching}

Levels of confidence $(0-5,5$ being most confident) to provide vital and non-vital bleaching varied between the dental schools. Cardiff students were the least confident (mean level 0.76 for vital and 1.02 for nonvital). Cork students were by far the most confident, with a mean level of 3.11 and 3.22 for vital and nonvital bleaching respectively. Malmö students showed similar levels to Cardiff with a mean response of 1.03 for vital and 1.12 for non-vital. All students claimed to feel more confident about providing non-vital bleaching than vital bleaching. On whether they would consider providing vital tooth bleaching for patients after qualification, $85 \%$ of students $(n=99)$ said they would provide this treatment. Figure 2 shows how students responded when asked if they felt they know

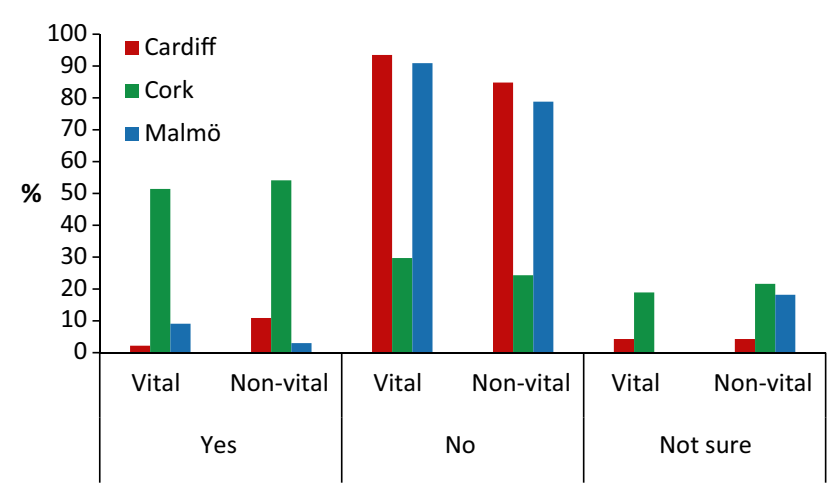

Fig. 2. Do students feel they know enough about bleaching to provide it when qualified? enough about bleaching to provide it in practice next year. Over $50 \%$ of Cork students responded positively, whereas over $75 \%$ of both Cardiff and Malmö students said they do not know enough to provide these treatments.

Attitudes to provision of bleaching and recommendations to patients

Table 1 shows how students responded when questioned how they would advise a patient if asked about home kits for tooth whitening. Cardiff students appear to be most discouraging in this situation with no students 'encouraging their use' and $72 \% \quad(n=33)$ discouraging them. The majority of Malmö students also discouraged their use. However, 30\% $(n=10)$ of Malmö students claimed not to know enough to answer the question. This is a very different response to Cork students where only $8 \%(n=3)$ discourage them, with $73 \%(n=27)$ encouraging their use with caution.

Table 2 illustrates whether students see themselves having their own teeth bleached in the future or whether they have already received bleaching on their teeth. Cardiff and Malmö students show similar levels of past bleaching treatments $(11 \%$ and $12 \%$ respectively), whereas many more Cork students have had their teeth bleached $(43 \%)$. These attitudes are repeated when asking about future plans. Cardiff students are the least likely to see themselves bleaching their teeth in the future $(<50 \%)$, much different compared with Cork, where $80 \%$ can see themselves having this treatment. Fifty-five per cent of Malmö students could see themselves using bleaching on their own teeth in the future.

\section{Teaching received in bleaching}

Both Cardiff and Malmö students received no didactic teaching on any bleaching techniques, whereas most Cork students said they had received $2 \mathrm{~h}$ on vital and $\mathrm{l}$ h on non-vital bleaching. Similarly, neither Cardiff nor Malmö students had any clinical experience of providing bleaching, compared with Cork students, where $30 \%$ of them had carried out non-vital bleaching treatments on patients.

Students were asked to list any vital bleaching techniques that they were aware of. Results from this are displayed in Table 3. Cork students knew of the greatest variety of techniques. 
Table 1. Students' advice to patients on home whitening kits ('over the counter' products)

\begin{tabular}{|c|c|c|c|c|c|c|}
\hline \multirow{2}{*}{$\begin{array}{l}\text { Advice to patients on home whitening kits } \\
\text { Encourage use }\end{array}$} & \multicolumn{2}{|c|}{ Cardiff $n(\%)$} & \multicolumn{2}{|c|}{ Cork $n(\%)$} & \multicolumn{2}{|c|}{ Malmö $n(\%)$} \\
\hline & $0(0)\}$ & \multirow[t]{2}{*}{$10(22)$} & $3(8)$ & \multirow[t]{2}{*}{$30(81)$} & $1(3)\}$ & \multirow[t]{2}{*}{$6(18)$} \\
\hline Encourage with caution & $10(22)^{\gamma}$ & & $27(73)^{\}}$ & & $5(15)^{\jmath}$ & \\
\hline Discourage their use & $25(54)\}$ & \multirow[t]{3}{*}{$33(72)$} & $2(5)\}$ & \multirow[t]{3}{*}{$3(8)$} & $12(36)\}$ & \multirow{3}{*}{$17(52)$} \\
\hline Strongly discourage use & $8(17)\}$ & & $1(3)\}$ & & $5(15)\}$ & \\
\hline Do not know enough to answer & $3(7)$ & & $3(8)$ & & $10(30)$ & \\
\hline
\end{tabular}

Table 2. Student attitudes to bleaching of their own teeth

\begin{tabular}{llccc}
\hline & Response & $\begin{array}{c}\text { Cardiff } \\
n(\%)\end{array}$ & $\begin{array}{l}\text { Cork } \\
n(\%)\end{array}$ & $\begin{array}{c}\text { Malmö } \\
n(\%)\end{array}$ \\
\hline $\begin{array}{llccc}\text { Students who } \\
\text { have had their teeth }\end{array}$ & Yes & $5(11)$ & $16(43)$ & $4(12)$ \\
bleached in the past & No answer & $01(89)$ & $20(54)$ & $29(88)$ \\
Number of students who & Yes & $21(46)$ & $28(76)$ & $18(0)$ \\
$\begin{array}{l}\text { see themselves having } \\
\text { their teeth bleached }\end{array}$ & No & $25(54)$ & $7(19)$ & $15(45)$ \\
in the future & No answer & $0(0)$ & $2(5)$ & $0(0)$ \\
\hline
\end{tabular}

Table 3. Vital bleaching techniques students were aware of

\begin{tabular}{lrrr}
\hline & \multicolumn{3}{c}{$\%$ of students } \\
\cline { 2 - 4 } Bleaching technique & Cardiff & Cork & Malmö \\
\hline Home kits & 11 & 43 & 0 \\
Bleaching trays & 36 & 24 & 27 \\
Nightguard & 11 & 5 & 0 \\
Hydrogen peroxide & 17 & 3 & 24 \\
Carbamide peroxide & 4 & 3 & 3 \\
Bleaching gel & 0 & 11 & 0 \\
In office & 30 & 24 & 0 \\
In office: Heat activated & 0 & 3 & 0 \\
In office: Power bleaching/light/laser & 17 & 57 & 18 \\
Customised trays to take home & 7 & 57 & 3 \\
Whitening strips & 0 & 30 & 0 \\
Toothpastes & 0 & 0 & 3 \\
Sodium peroxide & 0 & 0 & 6 \\
No answer & 26 & 8 & 39 \\
\hline
\end{tabular}

\section{Awareness of restrictions on the use of bleaching products}

Figure 3 shows the proportions of students in each dental school that are aware of current restrictions on the use of bleaching agents. Cork students (84\% $n=32)$ were more aware than those in Cardiff $(50 \% n=23)$ and Malmö $(0 \%)$. Students who answered 'yes' were then asked to indicate what they understood about these restrictions. Fifty-five per cent of Cork students

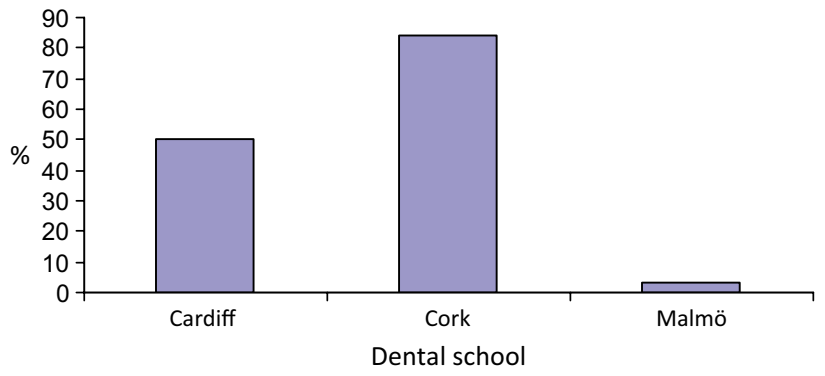

Fig. 3. Proportion of students aware of any current European Union restrictions on bleaching agents.

$(n=17)$ and $53 \%$ of Cardiff students $(n=12)$ answered that bleaching is illegal over a very low concentration, some specifying this level of a maximum of $0.1 \%$ hydrogen peroxide. Other responses given by Cardiff students included thoughts that bleaching is considered to be illegal by the Local Health Board (18\%), illegal in the NHS (13\%) and illegal by EU law (9\%). In Cork, other answers included that $35 \%$ hydrogen peroxide is illegal $(10 \%)$, bleaching agents are banned $(7 \%)$, it is illegal by EU law $(7 \%)$ and there are complications between medical and cosmetic licensing (7\%).

\section{Management of simulated clinical scenarios}

Scenario \#1 Respondents were asked what treatment they would provide for a patient who is complaining of a discoloured maxillary left lateral incisor following successful root canal therapy and placement of a palatal glass-ionomer restoration.

1 The most common response for all the schools was to provide non-vital bleaching: $48 \%(n=22)$ Cardiff; $89 \%(n=33)$ Cork; and 64\% Malmo $(n=21)$;

2 Other responses from Cork students were minimally destructive: including composite build-ups, replacement of the glass-ionomer with composite and internal with external bleaching; 
3 Apart from non-vital bleaching, remaining Cardiff responses were mainly destructive with $22 \%(n=10)$ suggesting a crown or veneer and $2 \%(n=1)$ suggesting a post-crown. Eleven per cent $(n=5)$ would replace the glass-ionomer with composite;

4 Fifteen per cent $(n=5)$ of Malmö students would treatment plan a crown or veneer, while $18 \%(n=6)$ would replace the glass-ionomer with composite.

Scenario \#2 Students were also asked what treatment they would provide for a pregnant woman who would like her moderately stained upper anterior teeth to be whiter. These teeth were restoration-free and cariesfree, and were vital with no apical or periodontal pathology.

1 Twenty per cent $(n=9)$ of Cardiff students, $14 \%$ $(n=5)$ Cork students and $15 \% \quad(n=5)$ Malmö students would defer treatment until the pregnancy was completed;

2 Thirty-three per cent $(n=12)$ of Cork students said they would provide bleaching, compared with lower levels $9 \%$ of Cardiff $(n=4)$ and $15 \%$ of Malmö $(n=5)$ students.

3 The most common response from Cork was vital bleaching $(33 \%, n=12)$, whereas in Cardiff it was provision of a scale and polish $(24 \%, n=11)$ and in Malmö bleaching after pregnancy $(18 \%, n=6)$.

4 Cardiff students were the only respondents to suggest providing microabrasion $(11 \%, n=5)$ and veneers $(2 \%, n=1)$.

\section{Discussion}

In this study, a questionnaire was used to collect data, distributed to final-year dental students. Responses were highest from Cork where students could be targeted in seminars, compared with those in Cardiff and Malmö where students were more dispersed. This method was an appropriate way of gaining information from a large number of students and increasing sample size $(16,17)$. An interview technique would have been hard to arrange and too time-consuming together with incurring greater cost. Providing a questionnaire allowed respondents to answer questions in their own time and decreased bias created in interviews where random and systematic error can occur (18). However, using a questionnaire to gain information relies on respondents being honest in their answers. Data is also limited by the questions provided and answers given.
Mean values rather than median values were reported for confidence levels in students although data were not truly continuous (respondents were given option of numbers 0-5). Nevertheless, the mean results provide a useful idea of the amount of confidence students have in providing bleaching where the mode or median would have been less useful.

These students were chosen at this stage of their careers as they are the closest cohort to qualification and their current opinions are likely to continue past graduation. Cardiff, Cork and Malmö dental schools provided a range of opinions from diverse geographical regions around Europe, where each country is a member of the EU and subject to EU regulations. However, with recent regulations surrounding the supply and use of hydrogen peroxide over $0.1 \%$ (1114) and different implications/interpretations of this in each country, attitudes have been found to vary between the students.

Cardiff students are under the greatest restrictions, given the interpretation of the European Cosmetics Directive (11). Let alone this, the General Dental Council (the UK dental regulatory body that also issues guidance on dental school education) does not include the teaching of bleaching in their document 'The First Five Years' (19). Locally, the provision of bleaching treatments within the Cardiff Dental Hospital is prohibited by the University Health Board. Conversely, Cork students are given formal teaching of bleaching. In Malmö, the students are not given any specific teaching on tooth whitening; however, as bleaching agents are classified as 'medical devices', the treatment is available and students are able to carry it out (14).

There was a tendency for Cork students to have a more positive attitude towards tooth whitening than both Cardiff and Malmö students, including on bleaching their own teeth. More Cork students $(44 \%)$ than those at both other dental schools (Cardiff $11 \%$, Malmö $12 \%$ ) had previously had their teeth bleached and were also most likely to have the treatment in the future (Cork $80 \%$, Malmö $58 \%$, Cardiff $46 \%$ ). This is also apparent for home whitening kits where a far greater proportion of Cork students than Cardiff and Malmö students would encourage patients to use them if asked. Literature available shows that Cardiff and Malmö students could be right to discourage their use with studies finding that those providing a mouthpiece to mould (not custom made) can allow the bleach to come into contact with and irritate the gingivae (20). As well, 
the bleach is usually of a low concentration, making the treatment less effective (20). Lack of clinical evidence is available regarding the safety and efficacy of these products, with many studies supported by the manufacturers $(21,22)$. As a result, it would be appropriate to discuss these problems with patients and avoid encouraging their use. When asked about the safety of vital tooth bleaching, more Cork students than Malmö and Cardiff students regarded vital tooth bleaching as being safe, with only $36 \%$ of the Swedish students agreeing with the statement (70\% Cardiff and $77 \%$ Cork). However, Malmö students could be right to be wary of a treatment that they know little about and have had no experiencing in doing on patients. Vital tooth bleaching has side effects, the most common being post-treatment tooth sensitivity (9).

High proportions of students were shown to be wary of offering treatments, including bleaching to a pregnant patient complaining of discoloured teeth. The literature is also divided on opinion on this topic, with a review article listing pregnancy as a contraindication (23), whereas Haywood (24) states that there is no scientific evidence for pregnancy to be a contraindication to bleaching treatments. Haywood does however say that he would not carry out whitening treatments on a pregnant female to remove the worry that the bleaching could be blamed for any problems with the pregnancy or baby and could also exacerbate pregnancy gingivitis (24). This shows how the literature cannot be relied on for answers, and at some point, the dentist must make the choice themselves - albeit with caution.

As Cardiff and Malmö students are less familiar and less positive towards bleaching treatments than Cork, it is appropriate to assume that on graduation, these students will treatment plan more crowns and veneers than bleaching or even discourage patients from treatment. This has many implications as a result of the removal of tooth tissue for these treatments. Future replacements of crowns or veneers with or without endodontic treatment are expensive and time-consuming, and patients should be made aware of this when these restorations are planned for discoloured teeth. Dunne and Miller (25) found that in a period of $5^{1 / 4}$ years, $11 \%$ of veneers fitted debonded or were removed. As well as this, follow-up studies of porcelain veneer placement have highlighted ongoing maintenance issues with veneers $(26,27)$ Crowns are also not guaranteed for life and at some point are likely to need replacing. With over $1.2 \mathrm{~mm}$ of tooth requiring removal for a porcelain fused to metal crown (28), the tooth becomes more vulnerable, and the irritation caused to the pulp can lead to pulp death and endodontic problems (7). On the other hand, if bleaching is provided tooth tissue is not removed but potential risks must be addressed, and the patient warned of these. Concerns have been raised surrounding potential for pulp death following some methods of tooth whitening (29) particularly those which involve heat and light; however, this is very rare and most side effects are reversible such as sensitivity and mucosal irritation. Cervical root resorption has also been found to be an uncommon risk associated with internal (non-vital) bleaching (9) Irreversible potential risks involved with bleaching, both vital and non-vital, seem far less common and the treatment considerably less invasive than the provision of crowns or veneers. As a result, it seems sensible to attempt bleaching before deciding on crowns or veneers; however, this may not be the case for Cardiff and Malmö students who on graduation have had little or no experience in considering bleaching as a treatment option.

With the increasing demand from patients for whiter teeth and the non-destructive nature of tooth whitening, there is a potential need for more teaching of bleaching in European dental schools $(4,5)$. Dental educators need to make progression in the curriculum when patients' needs and demands change, rather than merely with advances in commercial developments (15). This is important to prevent unnecessary destruction of tooth tissue when other viable treatment options are available, as shown with Cardiff students suggesting far greater destructive treatments including postcrowns when the patient complaint is a discoloured, root treated tooth. When these other options become included in curricula, the students as qualified dentists will consider less destructive treatments.

\section{Conclusions}

This study has demonstrated variations in the teaching of bleaching techniques and the attitudes of students from three European dental schools towards this treatment. Findings showed that Cork dental students had the most positive attitude towards tooth whitening and it safety, while being most keen to provide these treatments after qualification. Cardiff and Malmö dental students gave similar responses, with comparable lower levels of confidence in providing bleaching 
treatments, lack of knowledge and number of students wanting to provide whitening treatments after qualification. Malmö students had the least knowledge of restrictions in place surrounding bleaching agents; probably owing to bleaching products being classified as 'medical devices' in Sweden in contrast to the difficulties surrounding the classification of bleaching as a 'cosmetic' in the United Kingdom. With increasing patient demand for aesthetic treatments, there is a potential need for further teaching on tooth whitening techniques. Dental students need to be best prepared to meet the needs of their future patients. Non-invasive techniques such as tooth whitening offer conservative treatment alternatives and avoid more destructive techniques such as veneers or crowns.

\section{Acknowledgments}

We gratefully acknowledge the assistance of all those who took the time to complete our questionnaires.

\section{References}

1. Kelly M, Steele J, Nuttall N, Bradnock G, Morris J, Nunn J et al. Adult Dental Health Survey- Oral Health in the United Kingdom 1998. London: The Stationery Office, 2000.

2. Whelton H, Crowley E, O'Mullane D, Woods N, McGrath C, Kelleher V et al. Oral Health of Irish Adults 2000-2002. Department of Health and Children. Dublin: Brunswick Press Ltd, 2007.

3. Douglass CW, Jette AM, Fox CH, Tennstedt SL, Joshi A, Feldman HA et al. Oral health status of the elderly in New England. J Gerodontol. 1993;48:M39-M46.

4. Pretty IA, Brunton P, Aminian A, Davies RM, Ellwood RP. Vital tooth bleaching in dental practice: biological, dental and legal issues. Dent Update. 2006;33:422-432.

5. Joiner A. The bleaching of teeth: a review of the literature. J Dent. 2006;34:412-419.

6. Plotino G, Buono L, Grande NM, Pameijer CH, Somma F. Nonvital tooth bleaching: a review of the literature and clinical procedures. J Endod. 2008;34:394-407.

7. Cheung GS, Lai SC, Ng RP. Fate of vital pulps beneath a metalceramic crown or a bridge retainer. Int Endod J. 2005;38: 521-530.

8. Lynch CD, McConnell RJ. The use of micro-abrasion to remove discolored enamel: a clinical report. J Prosthet Dent. 2003;90:417-419.

9. Dahl JE, Pallesen U. Tooth bleaching - a critical review of the biological aspects. Critical Reviews Oral Biology Med. 2003; 14:292-304.

10. Tredwin CJ, Naik S, Lewis NJ, Scully C. Hydrogen peroxide tooth-whitening (bleaching) products: review of adverse effects and safety issues. Br Dent J. 2006;200:371-376.
11. European Commission. 1976. Council Directive: on the approximation of the laws of the Member States relating to cosmetic products. (76/768/EEC). [WWW] <URL: http:// ec.europa.eu/enterprise/sectors/cosmetics/documents/directive/> [Accessed 9th April 2010].

12. Morris CD. Tooth whiteners - the legal position. Br Dent J. 2003; 194:375-376.

13. Irish Medicines Board. Legal status of tooth whitening products. 25th January 2005.

14. Wallman C. Materials for tooth whitening. Publication no. 2008-123-9. Sweden: Social Styrelsen, Learning Centre for Dental Materials; 2008. (In Swedish).

15. Lynch CD, McConnell RJ, Wilson NHF. Trends in the placement of posterior composites in dental schools. J Dent Educ. 2007;71:430-434.

16. Blaxter L, Hughes C, Tight M. How to research, 3rd edn. Berkshire, England: Open University Press, 2006.

17. Oppenheim AN. Questionnaire design, interviewing and attitude measurement. New edition. London: Continuum; 2003.

18. Meadows KA. So you want to do research? Questionnaire design Br J Commun Nursing. 2003;8:562-570.

19. General Dental Council. The first five years, 3rd edn (interim). London: GDC; 2008.

20. Matthews M. Cosmetic dentistry: tooth whitening (safety and efficacy reports). Plast Reconst Surg. 2001;108:1436-1437.

21. Kugel G, Aboushala A, Zhou X, Gerlach RW. Daily use of whitening strips on tetracycline-stained teeth: comparative results after 2 months. Compend Contin Educ Dent. 2002;23:29-34.

22. Demarco FF, Meireles SS, Masotti AS. Over-the-counter whitening agents: a concise review. Braz Oral Res. 2009;23:64-70.

23. Sulieman M, Addy M, MacDonald E, Rees JS. The effect of hydrogen peroxide concentration on the outcome of tooth whitening: an in vitro study. J Dent. 2004;32:295-299.

24. Haywood VB. A comparison of at-home and in-office bleaching. Dent Today. 2000;19:44-53.

25. Dunne SM, Millar BJ. A longitudinal study of the clinical performance of porcelain veneers. Br Dent J. 1993;174: 317-321.

26. Peumans M, De Munck J, Fieuws S, Lambrechts P, Vanherle G, Van Meerbeek B. A prospective ten-year clinical trial of porcelain veneers. J Adhes Dent. 2004;6:65-76.

27. Burke FJ, Lucarotti PS. Ten-year outcome of porcelain laminate veneers placed within the general dental services in England and Wales. J Dent. 2009;37:12-24.

28. Blair FM, Wassell RW, Steele JG. Crowns and other extracoronal restorations: preparations for full veneers crowns. $\mathrm{Br}$ Dent J. 2002;192:561-571.

29. Sulieman M, Addy M, Rees JS. Surface and intra-pulpal temperature rises during tooth bleaching: an in vitro study. $\mathrm{Br}$ Dent J. 2005;199:37-40.

Correspondence: Christopher D. Lynch, Cardiff University School of Dentistry, Heath Park, Cardiff, CF14 4XY, UK.

E-mail: lynchcd@cardiff.ac.uk 